\title{
The Workflows of 3D Digitizing Heritage Monuments
}

\author{
Hung-Ming Cheng \\ China University of Technology
}

Taiwan

\section{Introduction}

Digitizing heritage monuments is a process of spatial data acquisition, geometry modelling, digital archiving and web-based representation. Moreover, there are several survey and digitizing techniques working and developing such as traditional manual methods, topographic methods, photogrammetric methods and scanning methods. The most popular on application and developing is 3D laser scanning technology right now. Especially for outdoor space and historical building, the laser scanner is an appropriate tool for the whole process of $3 \mathrm{~d}$ digitizing. Therefore in this study, the 3D digitizing heritage monuments take laser scanner as for developing an integrated procedure to digital recording and archiving of cultural heritages.

The whole 3D scanning process involves the three-dimensional digitization, digital data processing, archiving and management, representation and reproduction (Varady et al., 1997). The scanning action of acquiring, survey and recording spatial data for the determination of actual position and existing form, shape and size of a monument in 3D space at a particular given moment in time.

3D digitizing technologies apply in several fields, including manufacturing industry, medical sciences, entertainment industry and, cultural heritage (Addison \& Alonzo, 2006; Berndt \& Carlos, 2000; Levoy, 1999). In application of manufacturing industry, inspection probes and survey are substituted by non-contact laser scanning equipment that are often used for aero industry and automotive parts design and testing (Willis et al., 2007). And more computer aided design and reverse engineering are employed in a wide range of applications in the field of science and industry, together with animation techniques and WEB application (Fontana et al., 2002; Li et al., 2007; Pieraccini, 2001).

Cultural heritage transmits conventional environment and craftsman's experience in the civilization and cultural progress which needs to consider in specific way. (Arayici, 2007; Shih et al., 2007; Yilmaz et al., 2008) Owing to the longer process of confirming and the limitation of budget and timing, the preservation of historical architecture is not efficiently executed preservation. Moreover, natural disaster, such as earthquake, fire and accident collapse, caused historical architecture disappeared in one moment. Therefore, integrating digitizing techniques could help building preserved works at such limited opportunity. 
Traditional methods take time-consuming and present a number of evident limitations (Yilmaz et al., 2008). The way of survey and measuring of historical architecture are using photographing and manual tape method, then manually transferring these discrete numbers into engineering drawings by AutoCAD (Fischer \& Manor, 1999; Yilmaz et al., 2008). Although 2-dimensional drawings and graphics provide traditional support documents to rebuild historical architecture. They are not complete solutions to detailing spatial information without truly 3-dimensional model. Cultural heritage needs more advanced techniques to support preservation and conversation in cultural heritage (Arayici, 2007).

Digitizing historical cultural architecture is a trend on international preservation. Traditional tools using survey and probing in manuals couldn't correspond to preservation procedure in effective and efficient (Fontana et al., 2002; Li et al., 2007). It is necessary to consider an integrating mechanism with tools and procedures. Laser scanner is using the reflection and projection of laser beam and probing the difference of time. As the objects scanned by laser beam, the scanner machine calculates the distant of machine and objects. And by calibrating the ejection angle of laser beam, the laser scanner records the spatial data as data of point clouds. This study is employed 3D laser scanner with the high quality digital camera that can reach more than 1000 meters. And the inaccuracy of survey result is less than $5 \mathrm{~mm}$. For the thumb of digitizing, acquiring surface data of building are the most important of heritage preservation (Monga \& Benayoun, 1995).

For the main purpose of digitizing, the 3D spatial data of cultural heritage needs extracted for $3 \mathrm{~d}$ document application. Hence, digitizing techniques are considerably procedure in systematic and reasonable than those isolating in machine body or limited to people training. The whole workflow starts an investigation of survey technology and reverse engineering which is more mature field to utilize laser scanning technology. After comparing the techniques of laser scanner and photogrammetry application, laser scanner was chosen for more accurate, efficient, faster and reliable than other documentation techniques.

\section{Survey process}

Cultural heritage protection is an important issue in the world. The sustainable concept in public awareness and these kinds of monuments constitute an important part of our past. Digital 3d documentation presents a process of restore and protection which integrate the survey technique and building computing between reality and virtual world.

Heritage preservation is a continuous process with many data needs to integrate, acquire and analysis, which means a lot of construction data to be recorded. There are a serial of workflow and operation that include engineering surveying, drafting and design, monitoring for post-construction analysis (Berndt \& Carlos, 2000; Shih \& Wang, 2004). Recorded data are made by discrete manual 2D drawings have limitations in describing the allocation of geometries in 3D space. 3D data are intuitive, visualizing and continuous representation to simulate space characteristics which will be the best way to manipulate with architectural and historical senses. As such, we choose the 3D laser scanner of survey manner to reach our objective directly. 


\subsection{Laser scanner and operation system}

For reconstructing a 3D environment and architecture, Riegl LMS-Z420i with LiDAR system are chosen, which offers the most powerful in distant effective to capture the spatial data within point clouds format. The machine scans the surface of object to receive spatial data about 11,000 points per second with high precision up to $4 \mathrm{~mm}$. The field of view is $80 \times 360$ and the range is up to $1000 \mathrm{~m}$.

For each scanning mission, scanner machine needs portable computer with bundled operation software package "RiSCAN PRO" (Fig. 1.) to operate the scanner for acquiring high-quality 3D data in the field (Goldberg, 2001) [10]. By mechanically scanning the surface of object with the laser set, different sections of the object are sequentially acquired and cloud data are therefore generated. For the specific parts and detailed objects, scanner machine combines a concentrated shot function on these specific details with condense scanning of laser points.

The laser scanner can take advantage in the territorial field with reference points to connect difference station data. However, Target site have some obstacle views to disable cross scanning. The scanning plan therefore adopts higher view point to solve these limitations.

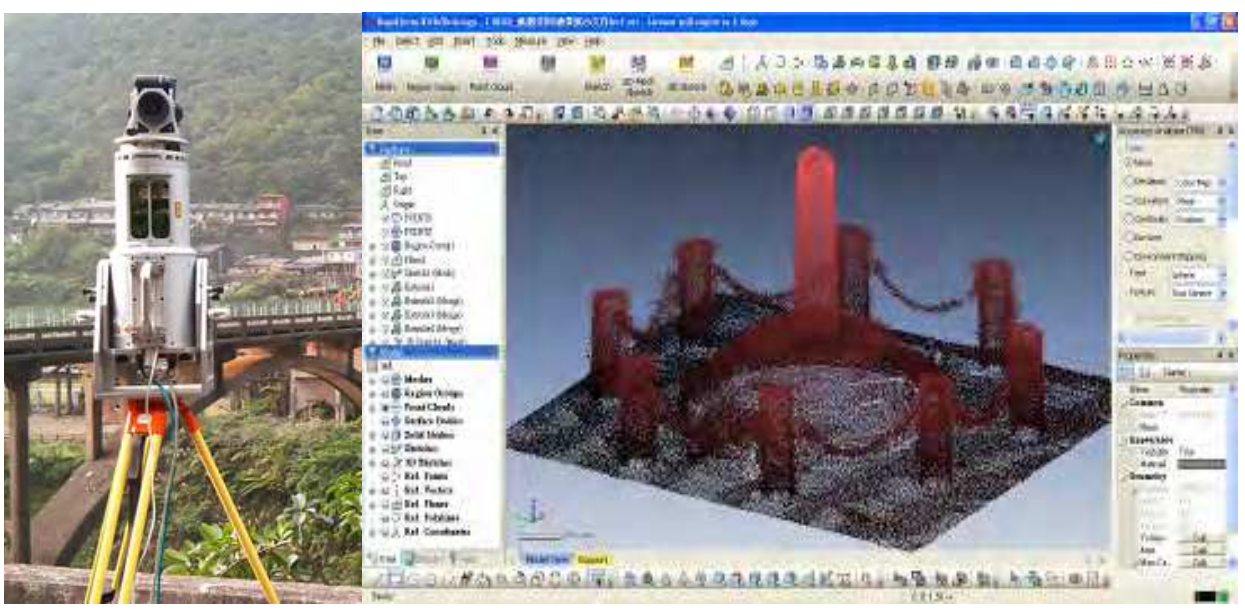

Fig. 1. Riegl LMS-Z420i \& software RiSCAN PRO

\subsection{Survey planning and scan works}

For acquiring the 3D data of real environments, an integrate scanning work has to planning for the whole archaeological objects from several different scanner stations which can combine a set of order of multiple view (scanning worlds). The major steps in combining multiple views is survey planning and accurate registration that related to information management in multiple views to be combined successfully. Such set of information is organized as token ring or star topology, and captured by multiple views in serial survey with registration targets. (Fig. 2.) 


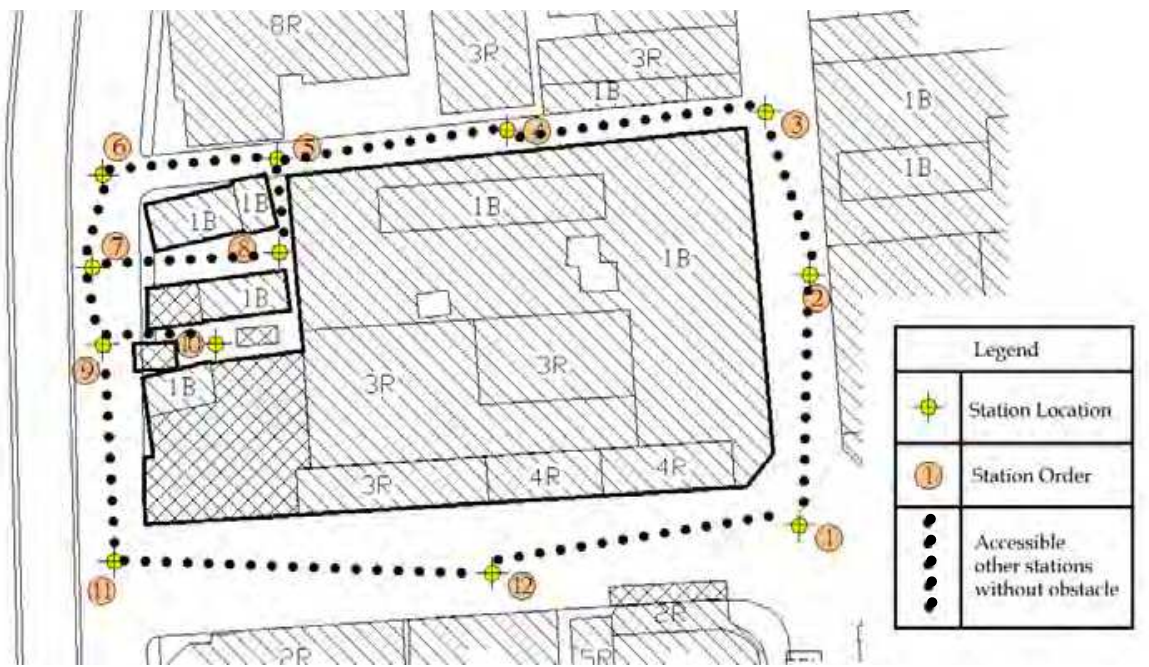

Fig. 2. Survey Planning for Scanner Station

For development of 3D scanner supports 360 degrees field-of-view, the scanner has to move around archaeological objects to complete exterior scan views with registration targets. The laser scanner is difficult to work at those buildings placed closely without appropriate station-locations on scanning and registration entire surroundings. Therefore, several higher locations are selected nearby those buildings. Moreover,, higher scanning locations are used to avoid obstructions problems and reduce numbers of scanning station. (Fig. 3.). These obstructions accessing stations are manipulated by special devices which can raise 3D scanner machine for survey higher and wider. Mobile vehicle carries lift-able device and work with more function controlled.

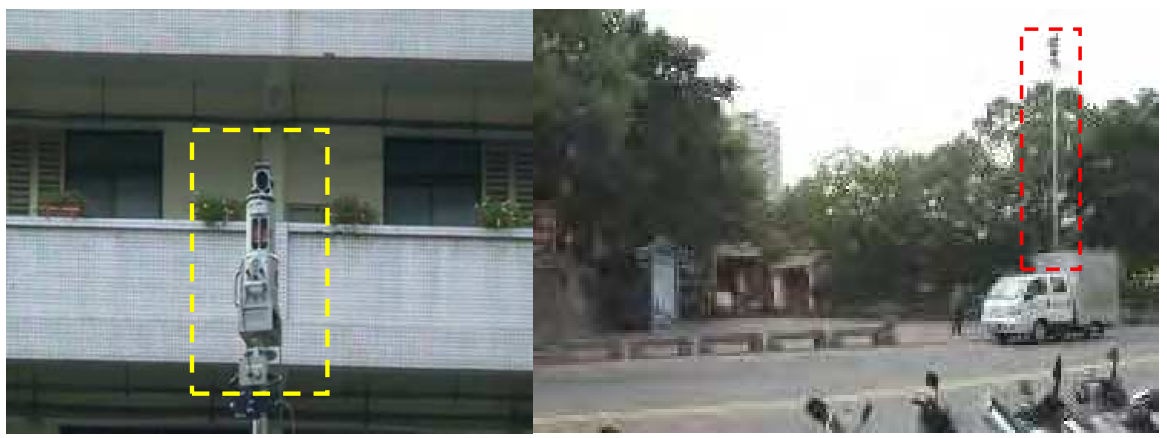

Fig. 3. The device raising 3D scanner and working on vehicle

For those objects to be scanned in a well-controlled environment (for example: indoor space and no obstruction problem), objects can be oriented scan completely without extra registration targets. However, ranged scanning is often incomplete for obstructions or lack of controlled-high-view scans at outdoor site. There is no way to solve such as problems until a lift-able car and movable support are made up. 
The device provides a carrier of 3D laser scanner with lift-able and stable character. It is not only fixing on the ground but also avoid to vibration. Furthermore, it can be controlled in height by expert experience for the best survey. The device with platform on the top can fixed scanner on the lift-pole. The each of multi-supported legs implements dynamic device for lift-up the truck that is for stable survey implementation without shaking by rubber tires. The lift-able device includes scissors-like instrument and platform, which includes a space for $3 \mathrm{~d}$ laser scanner instrument and multi-action kinematics extending the range of survey and reach proper height for advantage process. Therefore, the creative work includes liftable and stable character that is not only stability of scanner and also convenient adjusting height for the best survey efficiently. (Fig. 4.)
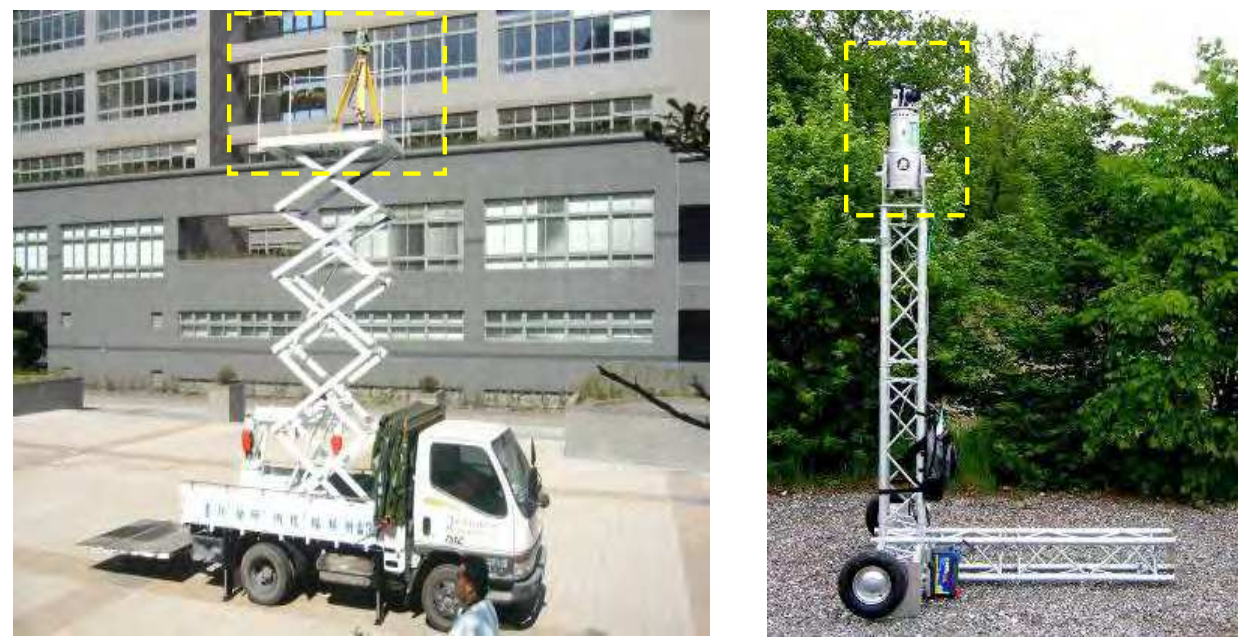

Fig. 4. lift-able car and movable support

\subsection{D data process}

The modelling operation starts to capture the feature of object. These features (for example, points, lines or components) will be extracted from images, enhancing the spatial characteristics and representing the coherence of geometry with mesh or solid of computer graphics algorithm (Datta, 2001; Li et al., 2007). The proposed feature extractors are adapted to solution software that includes CATIA and Rapidform XOR2 (Fig. 5). These softwares are based on the similarity of directional feature vector. For the 3D modelling (shape, surface and volume), there are some other options so called middleware of Reverse Engineering in order to develop Rapid Prototyping in design application (Fontana et al., 2002; Marschallinger, 1998; Monga, \& Benayoun, 1995) .

\section{The procedure of digitalizing archiving}

In digital processing of heritage monuments, inspection probes and survey probably met the difficult operation for physical environments. For application of digitizing archiving, 3D spatial information is transfer to different data formats as fundamental preservation. 


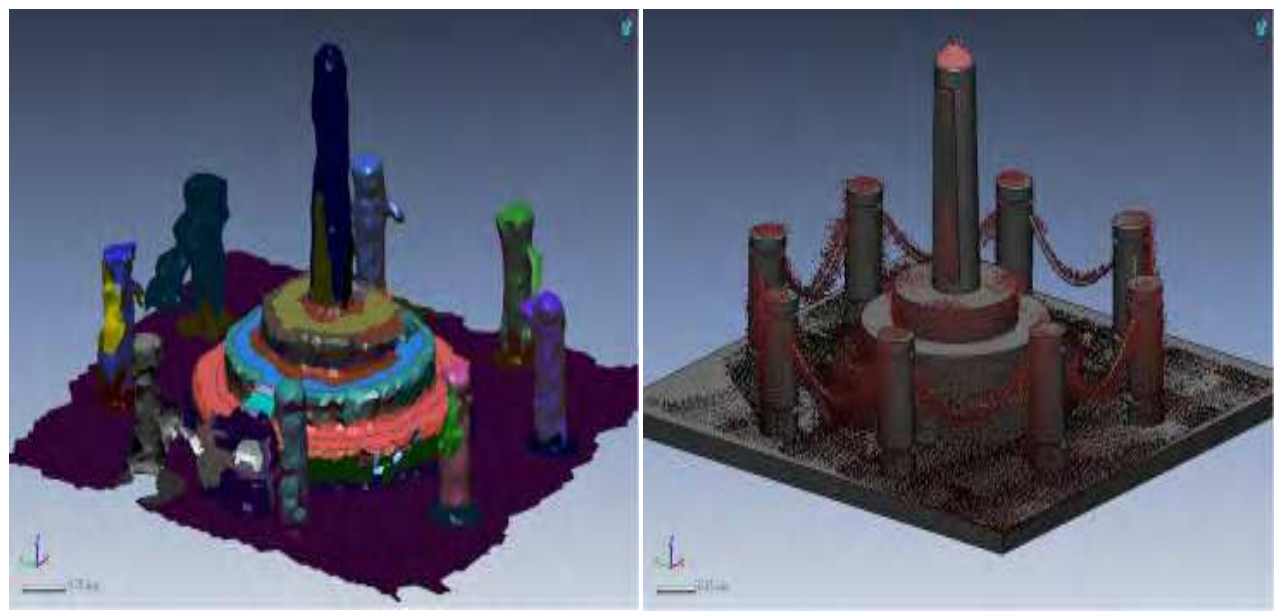

Fig. 5. Software Rapidform XOR2 processes the point cloud as mesh modeling

\subsection{Workflow of 3D scanning}

For the work flows of 3D data acquisition of cultural heritage, the quantity and density of point cloud control the detail of $3 \mathrm{~d}$ modelling by reverse engineering. In the registration of laser scanning, both software and hardware influence the representation and accurate of point cloud. Therefore, a procedure of laser scanning for different size and distant of heritage's objects is developed. In $3 \mathrm{~d}$ data acquisition of laser scanning, not only specific machine on manual to acquire $3 \mathrm{D}$ data is process but also different machine and software to registration point cloud are integrated. For the digital archiving of cultural heritage, these precious $3 \mathrm{~d}$ data can provide an original digital format for reconstructing physical heritage in future.

On the post operation phase, 3D modelling depends on the software of reverse engineering which is a from the survey technology for production. The software of reverse engineering (Rapidform XOR2) are manipulated for modelling the digital building which is a key process of industry utilization in physical form design. The whole processes are through surface analysis, holes filling, and rebuild the mesh models. The purpose of 3D modelling is building up full scale physical heritage in digital form that can apply to visualization and virtual reality on the Internet.

For the web representation, proprietary VR authoring tool is introduced to demonstrate the reconstructed results. The comprehensive virtual scene is then laid out in VR tool that is the web-base browser for navigating in $3 \mathrm{D}$ virtual world. For more application of VR, the data format of $3 \mathrm{D}$ point file is transformed to $3 \mathrm{D}$ boundary curve, parametric surface or replaced by adjusting points in original representation. In digital manipulation, many $3 \mathrm{D}$ forms and shapes are merged into virtual reality for representing new visual experience and immersive digital environment. As a result, rich illustrations (multimedia) are carried out through interactive manipulation in the Web. (Fig. 6). 


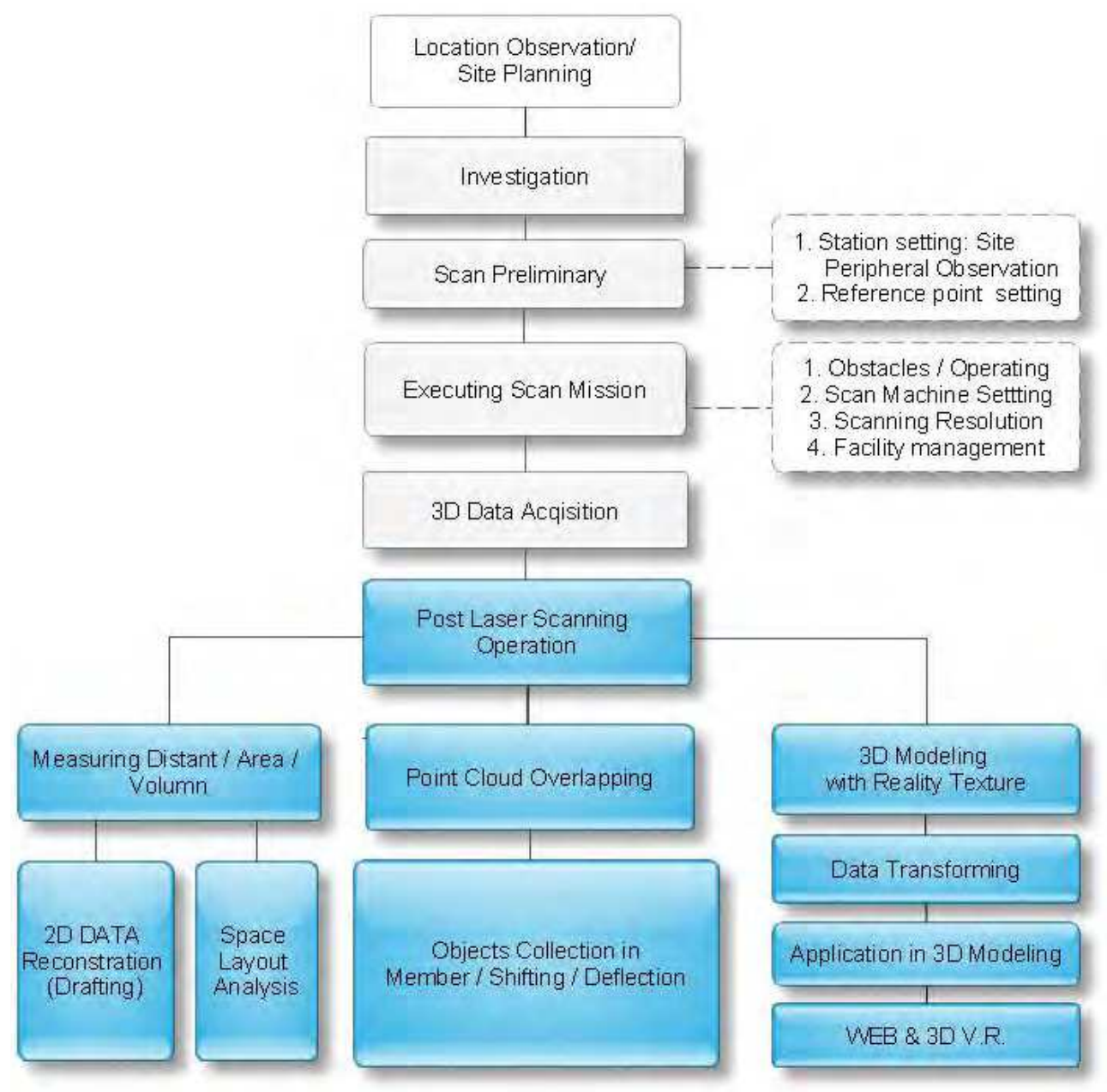

Fig. 6. Workflow of Digitizing

\subsection{Determining 3D data}

Determining 3D data is challenges work for digitizing cultural heritage whose purpose is to generate accurate model for more applications. 3D modelling of laser scanning is using the techniques of reverse engineering for processing points cloud overlapping (raw data), creating parametric surface and image texture mapping on objects. The main works are addressed on data transformation and 3D geometry rebuilt which are through automatic registration of points cloud, shape and form fitting and digital modelling. 
The point clouds are generated in local station centred coordinate systems whose limited field of views are captured from different viewpoints in order to obtain a full coverage of object surface. For reconstructing 3D model of object surface, these data of points cloud and images need to be registered in a single global coordinate system. For registration mission, point clouds from several different views have to align with target marks (at least 3 marks between 2 points data set merge) in iterative registration. (Fig.2.) Registration of image also determines the camera space parameters bringing one data set into alignment with the other.

On the other hand, the normalizing and corresponding on points cloud is another challenge. For registration assignment, overlapping of point cloud are critical processes for application of the laser scanning techniques which could be solved by increasing efficient ability of computer. However, point cloud overlapping consume more time on the normalizing and corresponding points cloud by filtering noise points and reducing points of some part manually.

For practice works, the operation software packages such like "RiSCAN PRO" are chosen for automatic registration of overlapping 3D point clouds. Dealing with post operational software, overlapping point cloud registration is easier to determine correspondences between different data sets representing the same free form objects from different scanning world.

Moreover, the other issues of 3D modelling have object surface modelling, 3D object recognition and texture mapping construction. The mission of surface reconstruction from scanned data and images are proposed methods as 4 stages (Fischer \& Manor, 1999). The first is extracting a continuous 3D boundary line (curve) by image post-processing techniques. The second is parameterizing a non-intersecting grid based on a numerical method. The third one is recognizing and creating a 3D parametric base surface whose 3D boundary was computed by the $1^{\text {st }}$ stage. The last one is projecting the internal $3 \mathrm{D}$ digitized points on the parametric base surface and calculating mesh parameterization. Following these processes, the mesh modelling is built up by approximating the 3D digitized points as a B-Spline surface while interpolating the extracted 3D boundary curve.

The processes of mesh modelling have to ensure the correct post-processing of the reconstructed mesh surface in CAD applications and the topology of the reconstructed mesh surface has to be correct. The mesh modelling method fall into three categories are current approaches in reversed engineering of point cloud reconstructed model. The methods for reconstructing triangle mesh surface from normalizing point cloud. Starting with a seed triangle, the 3D modelling builds a partially reconstructed triangle mesh by selecting a new point based on an intrinsic position of the point cloud.

The reconstructed mesh is essentially base for 3D modelling application, two-dimensional drafting and 3D web observation. For the practice assignment, package software "Rapidform XOR2" is adopted as tool to operate the 3D modelling missions. The process of 3D modelling is dealing with filtering noisy, sampling and smoothing, $3 \mathrm{~d}$ modelling analyze through mesh build up, surface analysis with region group and auto segment, mesh sketch with CAD manipulating, 2D boundary drafting, 3D editing tools and file export. (Table 1.) 


\begin{tabular}{|c|c|c|c|}
\hline Stages & Items & Illustrations & Description \\
\hline $\begin{array}{l}\text { File } \\
\text { import }\end{array}$ & $\begin{array}{l}\text { representation } \\
\text { of points } \\
\text { cloud }\end{array}$ & & $\begin{array}{l}\text { 1) Import .dxf file. } \\
\text { 2) Units choosing, } \\
\text { model scaling. } \\
\text { 3) zoom, viewpoint, } \\
\text { observation type }\end{array}$ \\
\hline Editting & $\begin{array}{c}\text { Filtering noise } \\
\text { points }\end{array}$ & Point cloud & $\begin{array}{l}\text { Tools for points } \\
\text { cloud: } \\
\text { Filter noisy, sampling, } \\
\text { smooth, filling hole... }\end{array}$ \\
\hline Surface & $\begin{array}{l}\text { Surface } \\
\text { forming and } \\
\text { analysis }\end{array}$ & 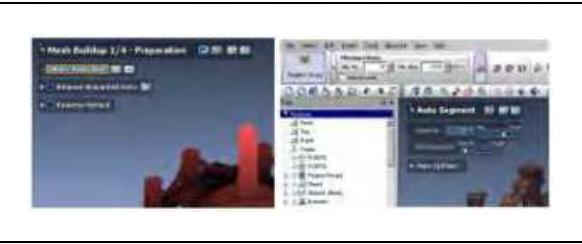 & $\begin{array}{l}\text { 1) Transforming } \\
\text { surface thru. Mesh } \\
\text { buildup. } \\
\text { 2) Analysis tools: } \\
\text { region group/ auto } \\
\text { segment... }\end{array}$ \\
\hline \multirow{2}{*}{$\begin{array}{c}3 \mathrm{D} \\
\text { modelling }\end{array}$} & $\begin{array}{l}\text { Surface } \\
\text { manipulating/ } \\
\text { 2D boundary } \\
\text { drafting }\end{array}$ & 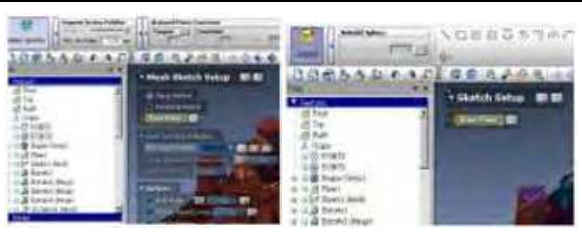 & $\begin{array}{l}\text { 1) Buildup 3D } \\
\text { boundary thru. Mesh } \\
\text { sketch. } \\
\text { 2) Based on the points } \\
\text { cloud, sketch 2D } \\
\text { boundary. }\end{array}$ \\
\hline & $\begin{array}{l}\text { 3D editing } \\
\text { tools }\end{array}$ & 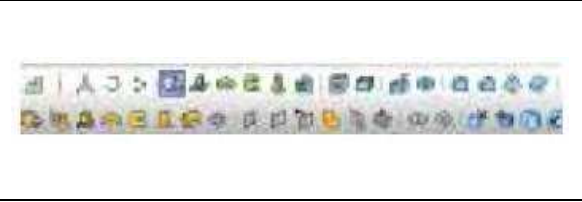 & \begin{tabular}{|c|} 
1) generating \\
geometry by \\
automatic recognizing \\
2) 3D tools: extrude, \\
loft...
\end{tabular} \\
\hline $\begin{array}{l}\text { File } \\
\text { output }\end{array}$ & $\begin{array}{l}\text { Export 3D } \\
\text { data file }\end{array}$ & 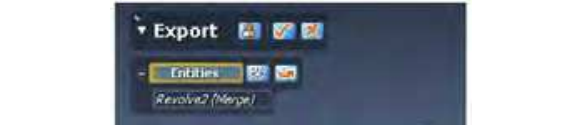 & $\begin{array}{l}\text { Thru. File/Export } \\
\text { export file format } \\
\text { "IGES". }\end{array}$ \\
\hline
\end{tabular}

Table 1. 3D modelling for "Rapidform XOR2 “

\subsection{Phase works of 3D scanning}

In this project, 3D laser scanner techniques are used to rebuild the objects of heritage, which includes an upright stone tablet, pavilion, bridge and historical building. (Table 2.) According to past experiments, this integrated approach is efficient and accurate. LiDAR (Laser Radar) technology could precisely digitize fine details and sculpted surfaces which are essential for modelling monuments and historical buildings. In the procedures of texture mapping, the raw data are processing from real picture and some statistics numbers of stations into images of point clouds, images of $3 \mathrm{~d}$ modelling. Furthermore, $3 \mathrm{~d}$ data representations can present several types of heritages which are interior, garden, monuments, building and bridge. 


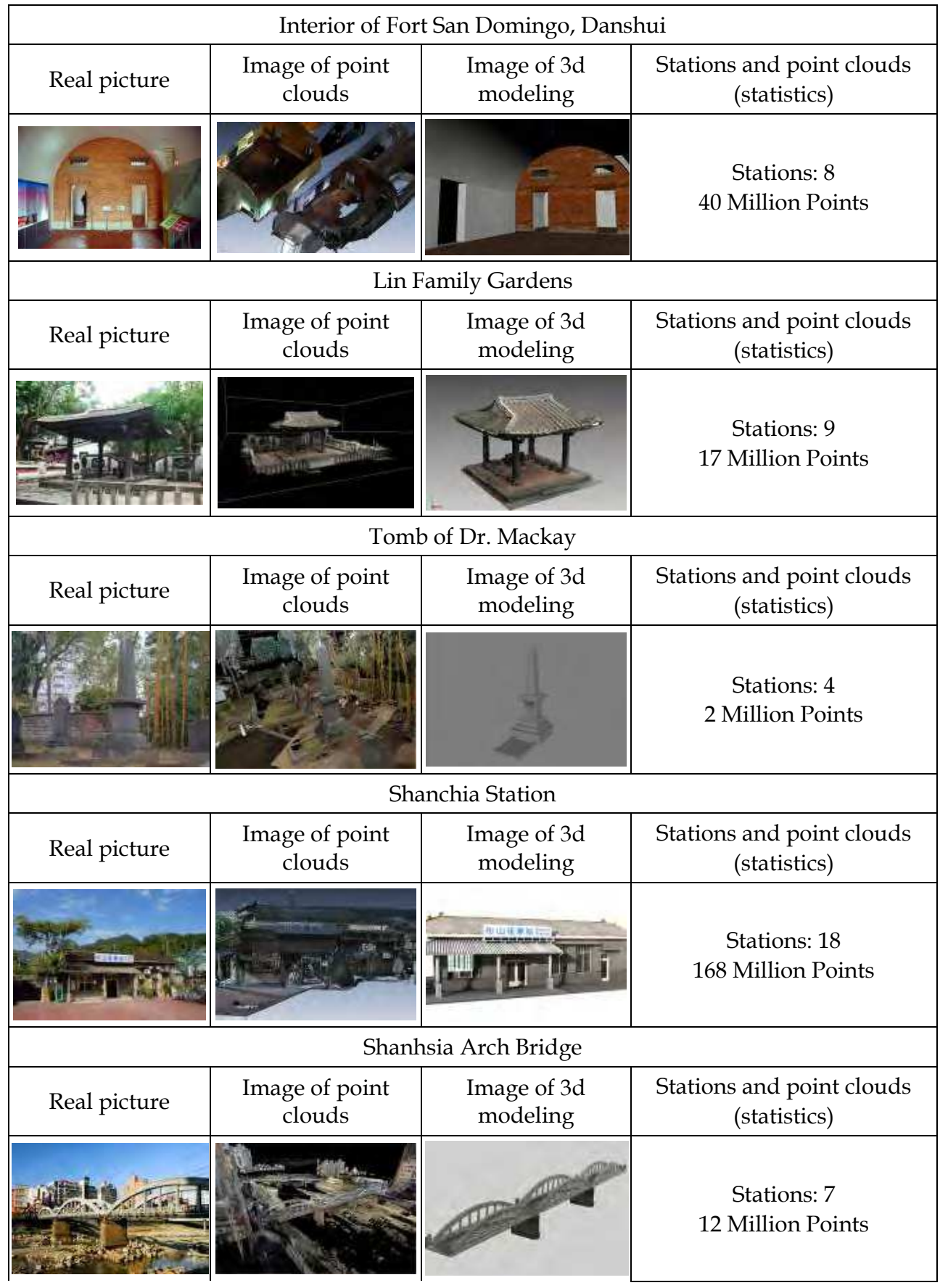

Table 2. Five Types of digitizing cultural heritages 


\section{Application in scanning technology}

Digital archiving has been applied on several purposes in heritage preservation recently. There are two issues for processing of digitizing project. The first is monitoring of cultural which is following currently reconstruction work. The second is trying to find out the data characters for decision supported making.

\subsection{Documentation and monitoring of cultural heritage}

Virtual preservation takes advantage of the expansion and long-term saving. Cultural heritage needs these data for sustainable monitoring. In particular, the heritages in real environment are irreversibly damaged by environmental disaster or atmospheric damages. Those damages sometime were discovered too late. High accuracy 3D scanning, at regular times, could detect deformations and cracks. These data of monitoring are the fundamental knowledge for reconstructing heritage.

The 3D documentation archives the spatial data of cultural heritage. Documentation should be considered as an integral part of a greater action in general documentation of the cultural heritage. Those data includes text, picture, music, and more other format media. These multi-format media with historical documentation, architectural documentation store a whole picture of cultural heritage.

On the other hand, cultural heritage protection is a key issue around the world today. Those issues evoke public awareness over recent years which address some important monuments of our past. The documentation and display of ancient artefacts and antiquities is an essential task in the field of cultural heritage preservation (Yilmaz et al., 2008). Digital archive of high quality three-dimensional models would give improvement in the restoration science field. Digital archives thus can be used as reference for monitoring and restoration of cultural heritages (Pieraccini et al., 2001). (Fig. 7.)

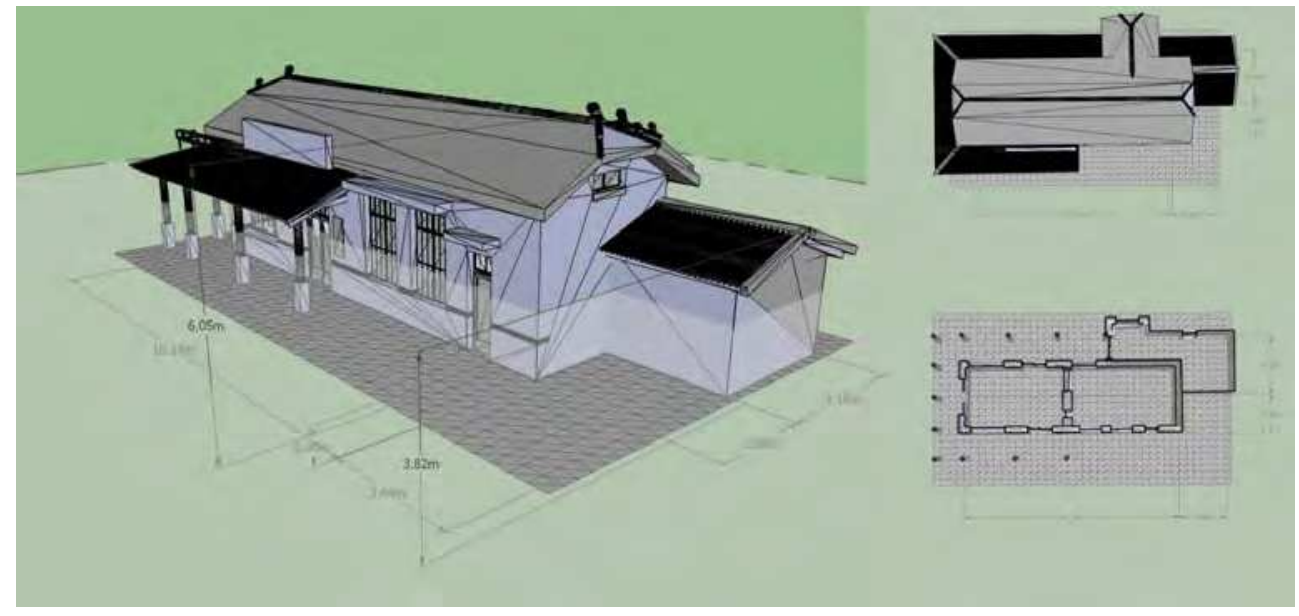

Fig. 7. 3D Documentation (Jing-Tong Train Station) 


\subsection{Data management and multimedia}

Multimedia (such as 3D scenes navigation, animation) has developed for two purposes. The first offers in showing the sequence of possibilities image sequences, where each image represents an option based on a set of parameters. As architects are interested in specific image, that shows the closest match between model and the virtual measurement. The 3D navigation also reveals an insight of spatial design thinking that cannot possibly be revealed through flat and analogue representation.

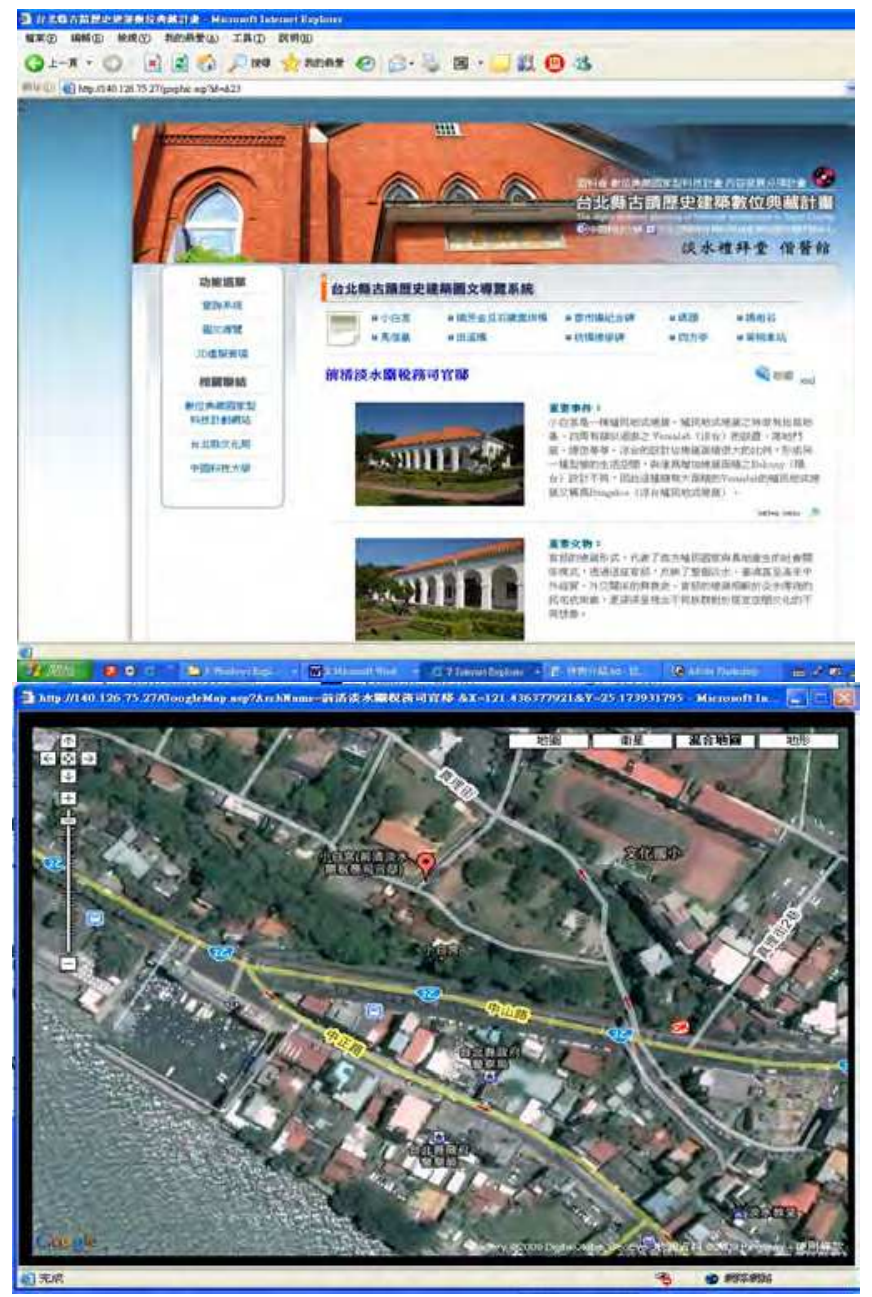

Fig. 8. Photo Picture and Texts Present in Webpage and GIS Applying Google Map

This project produces heritages in Taipei County establish archive of all the survey material combined with the work, that are integrated in the digital format for next application. Heritage materials are combined with historical document, physical situation and 
contemporary observation. Digitally managing materials have been essential programs that need to organize comprehensive representation in terms of the web environment to display accurate information (Fig. 8.). On the other hand, text, image and drawings are importance in design studio for representation issues. Consulted these data through the digital archives, the design can continuously work. Multimedia has been used to assemble these data for specific purposes including as-build environment representing or VR tour. These 3D digital data help design teamwork for next design decision making.

\section{Discussion}

Preserving and representing cultural heritage motivates the new technology for producing complex and heterogeneous data. For managing these data, digitalizing process is an essential task for the use and the diffusion of the information gathered on the field. These issues are discussed in terms of the concepts of digital archiving, 3D documentation and WEB application for the emergence of digitalization in recent years.

\subsection{Digital archiving in cultural heritage}

The jobs of digital archiving include several phases of the preserving, organizing and retrieving on the cultural heritage. 3D laser scanning technology evolves in the most diverse fields, an increasing number of cultural institutions take into consideration the need to capture 3D datasets of heritage assets. However, the digitizing procedures with $3 \mathrm{~d}$ laser scanning are very heterogeneous and complex, including not only the economic management and the logistic activities which take place in the computer labs, but also onstage artistic production and craft-made activities in workshops.

The whole process involves the three-dimensional digitization, digital data processing and storage, archival and management, representation and reproduction. The preservation methods for three-dimensional digitization are briefly reviewed that are applicable to cultural heritage recording.

\subsection{Survey technologies and other applications}

With recent developments in computer and information technologies, this well-known traditional method has been replaced with digital survey and Internet technology.

These new methods offer us new opportunities such as automatic orientation and measurement procedures, generation of 3D point-clouds data, digital surface modelling and WEB representation in cultural heritage. These methods and equipments commonly used for digitalizing buildings are: traditional manual surveying methods, photogrammetric methods, scanning methods and WEB database application. These methods determine the main data representation, the instruments limitation and the key points of each cultural heritage.

On the other hand, 3D laser scanning is an essential technology for territory survey that has become increasingly popular for 3D documentation. These techniques provide very dense $3 \mathrm{D}$ points on an object surface with high accuracy. In addition, the 3D model within digital image can be easily generated using generated 3D point cloud and recorded as vector measured drawing data. These large data must be processed by proper procedures for solving the work flow in order to connect human-machine interface and operation software. 
Current digital archiving has been carried out for the digital preservation and treatment of Cultural Heritage information. The development of computerized data management systems to store and make use of archaeological datasets is a significant task. For such application in the Internet, 3D WEB representation is a broadcasting platform for highlighting 3D spatial information browsing which should be processed on the phases of captured, structured, and retrieved in order to transform multimedia performances in cultural heritage for other application. The whole digital system need to compliant to every kind of Cultural Heritage site and allows management of heterogeneous data.

\section{Conclusion}

The laser scanning workflow develops three phases to initialize digitizing works. The first phase is $3 \mathrm{D}$ data acquisition which using the $3 \mathrm{~d}$ laser scanner to rebuild the surfaces of environment which are several stations of view to registration. The second phase is $3 \mathrm{D}$ modelling which is using the reverse engineering software to process those raw data (points of cloud). This phase mainly is data transformation and 3D geometry rebuild. (3) Web representation and others application: We procedure digitizing process to integrate 3D data and others media format (i.e. text, picture...) for navigating in World Wide Web. These 3D data are integrating into $2 \mathrm{D}$ graphic drawing and specific derails to present rich culture heritage.

Concluding current works, roadmap of digital archiving is proposed as 3 possible directions: The first direction considers Web visualization is an essential communication platform to represent 3D data in the world. These data are easy access and retrieve by Internet technology which also are unlimited time and place. The second direction is $3 \mathrm{D}$ laser scanners become an essential application from industry engineering to cultural heritage. The tools and theory are contributed to the heritage preservation and conservation. Furthermore, strategic applications on heritage preservation are developing for cultural creation industry. For the last direction is digital archiving, these data are formed a kind of "3D documentation of digital heritage". In the wide definition of conservation and preservation, 3D laser scanners grab the most formal appearance of heritage which includes more than primitives of geometry, shape, colour and texture.

In the future works, the scanning support tools of lift-able car and movable already integrate to the workflow of 3D laser scanning on heritage and historical architecture which is the best way to overcome visual (scanning accessing) obstacles. These support mechanisms in scanning workflow help digitizing physical environment successfully. In the process of digital archiving, managing and applicable technologies extend 3D data information system for digital museum in heritage preservation. Therefore, the spatial digital data with 3D character of culture heritage become virtual heritage.

\section{Acknowledgment}

This study is sponsored by the National Science Council for 2007-2008 National Digital Archive Program (NSC-96-2422-H-163-001, NSC-97-2631-H-163-001) and 2010 (NSC-992632-H-163-001), Taiwan. 


\section{References}

Addison, A.C. and Alonzo, C. (2006). The Vanishing Virtual: Safeguarding Heritage's Endangered Digital Record, in T. Kvan and Y. Kalay, (eds), Proceedings of New Heritage: Beyond Verisimilitude, pp.36-48, University of Hong Kong,

Arayici, Y. (2007). An approach for real world data modelling with the 3D terrestrial laser scanner for built environment, Automation in Construction, Vol.16, No.6, pp.816829 ,

Berndt, E. and Carlos, J. (2000). Cultural heritage in the mature era of computer graphics, IEEE Computer Graphics and Applications, Vol.20, No.1, pp.36-37,

Bhatti, A. Nahavandi, S. and Frayman, Y. (2007). 3D depth estimation for visual inspection using wavelet transform modulus maxima, Computers and Electrical Engineering, Vol.33, No.1, pp.48-57,

Bosche, F. and Haas, C. (2008). Automated retrieval of 3D CAD model objects in construction range images, Automation in Construction, Vol.17, No.4, pp.499-512,

Datta, S. (2001). Digital reconstructions and the geometry of temple fragments, The Proceedings of the 2007 international conference on digital applications in cultural heritage, pp.443-452, National center for research and preservation of cultural properties, Tainan, Taiwan,

Dorai, C., Weng, J., Jain, A. K. and Mercer, C. (1998). Registration and integration of multiple object views for 3D model construction, IEEE Transactions on Pattern analysis and Machine Intelligence, Vol.20, No.1, pp.83-89,

Fischer, A. and Manor, A. (1999). Utilizing image Processing Techniques for 3D Reconstruction of Laser-Scanned Data, CIRP Annals - Manufacturing Technology, Vol.48, No.1, pp.99-102,

Fontana, R. Greco, M. Materazzi, M. Pampaloni, E. and Pezzati, L. et. al. (2002). Threedimensional modelling of statues: the Minerva of Arezzo, Journal of Cultural Heritage, Vol.3, No.4, pp.325-331,

Goldberg, H.E. (2001). Scan Your Would with 3D Lasers, CADALYST Magazine, pp.20-28

Levoy, M.A. (1999). The Digital Michelangelo Project, Computer Graphics Forum, Vol.18, No.3, xiii-xvi(4)

Li, J. Guo, Y. Zhu, J. Lin, X. Xin, Y. Duan, K. and Tang, Q. (2007). Large depth-of-view portable three-dimensional laser scanner and its segmental calibration for robot vision, Optics and Lasers in Engineering, Vol.45, No.11, pp.1077-1087,

Marschallinger, R. (1998). A method for three-dimensional reconstruction of macroscopic features in geological materials, Computers $\mathcal{E}$ Geosciences, Vol.24, No.9, pp.875883 ,

Monga, O. and Benayoun, S. (1995). Using Partial Derivatives of 3D Images to Extract Typical Surface Features, Computer Vision and Image Understanding, Vol.61, No.2, pp.171-189,

Pieraccini, M. Guidi, G. and Atzeni, C. (2001). 3D digitizing of cultural heritage, Journal of Cultural Heritage, Vol.2, No.1, pp.63-70,

Shih, N.J, Wang H.J., Lin, C.Y. \& Liau, C.Y. (2007). 3D scan for the digital preservation of a historical temple in Taiwan, Advances in engineering software, Vol.38, No.7, pp.501512 , 
Shih, N.J., and Wang, P.H. (2004). Point-cloud-based comparison between construction schedule and as-built progress - a long-range 3D laser scanner's approach, Journal of Architectural Engineering, Vol.10, No.3, pp.98-102

Varady T., Martin R. \& Cox J. (1997) Reverse Engineering of Geometric Models -- an Introduction, Computer-Aided Design, Vol. 29, No. 4, pp.255-268,

Willis, A. Speicher J. \& Cooper D.B. (2007). Rapid prototyping 3D objects from scanned measurement data, Image and Vision Computing, Vol.25, No.7, pp.1174-1184

Yilmaz, H.M., Yakar M. \& Yildiz, F. (2008). Documentation of historical caravansaries by digital close range photogrammetry, Automation in Construction, Vol.17, No.4, pp.489-498 


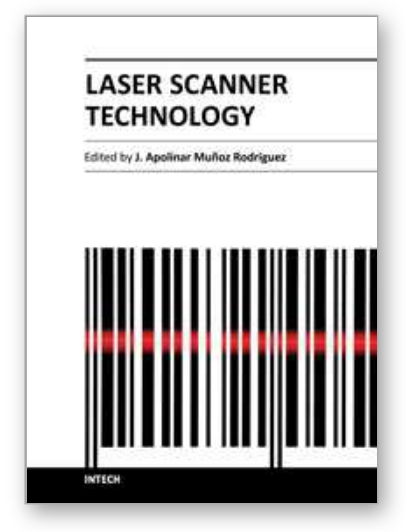

\author{
Laser Scanner Technology \\ Edited by Dr. J. Apolinar Munoz Rodriguez
}

ISBN 978-953-51-0280-9

Hard cover, 258 pages

Publisher InTech

Published online 28, March, 2012

Published in print edition March, 2012

Laser scanning technology plays an important role in the science and engineering arena. The aim of the scanning is usually to create a digital version of the object surface. Multiple scanning is sometimes performed via multiple cameras to obtain all slides of the scene under study. Usually, optical tests are used to elucidate the power of laser scanning technology in the modern industry and in the research laboratories. This book describes the recent contributions reported by laser scanning technology in different areas around the world. The main topics of laser scanning described in this volume include full body scanning, traffic management, 3D survey process, bridge monitoring, tracking of scanning, human sensing, three-dimensional modelling, glacier monitoring and digitizing heritage monuments.

\title{
How to reference
}

In order to correctly reference this scholarly work, feel free to copy and paste the following:

Hung-Ming Cheng (2012). The Workflows of 3D Digitizing Heritage Monuments, Laser Scanner Technology, Dr. J. Apolinar Munoz Rodriguez (Ed.), ISBN: 978-953-51-0280-9, InTech, Available from: http://www.intechopen.com/books/laser-scanner-technology/the-workflows-of-3d-digitizing-heritagemonuments

\section{INTECH}

open science | open minds

\section{InTech Europe}

University Campus STeP Ri

Slavka Krautzeka 83/A

51000 Rijeka, Croatia

Phone: +385 (51) 770447

Fax: +385 (51) 686166

www.intechopen.com

\section{InTech China}

Unit 405, Office Block, Hotel Equatorial Shanghai

No.65, Yan An Road (West), Shanghai, 200040, China

中国上海市延安西路65号上海国际贵都大饭店办公楼 405 单元

Phone: +86-21-62489820

Fax: +86-21-62489821 
(C) 2012 The Author(s). Licensee IntechOpen. This is an open access article distributed under the terms of the Creative Commons Attribution 3.0 License, which permits unrestricted use, distribution, and reproduction in any medium, provided the original work is properly cited. 